\title{
RUANG KERAGAMAN BERBASIS SOSIOKULTURAL, KAWASAN MUARA BARU
}

\author{
Jennifer ${ }^{1)}$, JM. Joko Priyono Santoso ${ }^{21}$ \\ ${ }^{1)}$ Program Studi S1 Arsitektur, Fakultas Teknik, Universitas Tarumanagara, jennifer_sdk@yahoo.com \\ 2) Program Studi S1 Arsitektur, Fakultas Teknik, Universitas Tarumanagara, jokop@ft.untar.ac.id
}

Masuk: 14-07-2020, revisi: 01-08-2020, diterima untuk diterbitkan: 24-09-2020

\begin{abstract}
Abstrak
Muara Baru merupakan salah kawasan terkumuh di Jakarta, padahal awalnya kawasan ini belum dipenuhi oleh permukiman. Namun semenjak terjadinya perkembangan pada kawasan industri pada akhir tahun 1980-an di Muara Baru, tingkat urbanisasi menjadi meningkat, sehingga kepadatan pada kawasan ini juga menjadi sangat tinggi. Hal ini sangat berdampak kepada masyarakat dalam aktivitas sehari-harinya, yaitu terciptanya eksklusi sosial antar masyarakat. Salah satu untuk menghilangkan rasa eksklusi sosial masyarakat Muara Baru adalah dengan cara meningkatkan modal sosiokulturalnya, karena itu perlu adanya investasi sosiokultural dalam pengembangan masyarakat Muara Baru. Sehingga perancangan bertujuan agar masyarakat kawasan Muara Baru dapat meningkatkan kualitas performa individu. Metode yang digunakan dalam penelitian ini adalah Metode Deskritif dan Metode Komparatif. Dari hasil penelitian ini, hasil yang diusulkan adalah "Ruang Keragaman Berbasis Sosiokultural", Kawasan Muara Baru. Program utamanya adalah sosial dan edukasi dalam basis sosiokultural, seperti adanya bazar kebudayaan mingguan. Hasil perancangan ini ditujukan untuk masyarakat, agar mereka dapat menghilangkan rasa eksklusi sosial, sehingga terbentuknya individu yang lebih produktif,dan perlahan mereka akan meningkatkan kawasan Muara Baru).
\end{abstract}

Kata kunci: arsitektur terbuka; eksklusi sosial; kawasan kumuh; sosiokultural

\begin{abstract}
Muara Baru is one of the largest slums area in Jakarta. At first, this area wasn't full of houses. But since late 1980s, development of industrial area in Muara Baru increase rapidly, the number of urbanizations has gone up. And the density in this area became very high. This has a huge impact on society in their daily lives, and this will create exclusion social between individuals. One of the ways to eliminate the exclusion social is increase the socio- culture asset, because there's needs for investation development of peoples in Muara Baru. So the project that will be built is aiming the people of the Muara Baru area can improve the quality of individual performance The method of research used in this project is descriptive method and comparative method. The result of this research is "Diversity Socioculture Space, Muara Baru". The main program in this project is social and education with socioculture concept, like having weekly culture bazzar. So the results of this design are aimed at the community, so that they can eliminate the sense of social exclusivity between individuals, and from the formation of productive individuals, so they will improve Muara Baru area.
\end{abstract}

\section{Keywords: open architecture; slums; sociocultural; social exclusion}

\section{PENDAHULUAN (11pt) Latar Belakang}

Awalnya kawasan Muara Baru belum pada akan penduduk. Namun pada akhir tahun 1980, Pembangunan Pelabuhan Samudera (PPS) Nizam Zachman sudah berada pada tahap I, dan pada tahun 1986 PPS sudah beroperasi dengan penuh. Semenjak terbangunnya PPS Nizam Zachman, pada akhir tahun 1980-an keadaan di kawasan ini menjadi ramai, orang-orang dari berbagai daerah mulai berdatangan dan menetap di kawasan ini. Urbanisasi meningkat dengan 
pesat, dan pada akhirnya tingkat kepadatan pada kawasan ini menjadi sangat tinggi. Permukiman pun perlahan-lahan berubah menjadi kumuh, dan lingkungan menjadi tidak kondusif. Hal ini tentunya akan mempengaruhi pengembangan masyarakat setempat, dan hanya akan memberikan jarak antar individu. Pada akhirnya, kawasan Muara Baru akan mencipatkan ruang eksklusif sosial.

\section{Rumusan Permasalahan}

Berdasarkan uraian latar belakang di atas, maka rumusan permasalahan yang ada dalam penelitian ini merupakan adanya ruang eksklusif pada masyarakat kawasan Muara Baru, sehingga pengembangan masyarakat setempat menjadi terhambat. Lalu program seperti apakah yang dibutuhkan di kawasan Muara Bar untuk mendorong pengembangan masyarakat setempat?

\section{Maksud dan Tujuan}

Berdasarkan uraian rumusan permasalahan di atas, maka maksud dalam penelitian ini adalah memberikan tempat berkumpul yang nyaman dan aman untuk masyarakat Muara Baru, dengan tujuan penelitian agar mereka dapat terlepas dari isu eksklusi sosial, sehingga mereka dapat meningkatkan kualitas perfomanya, dan menjadi individual yang lebih produktif.

\section{KAJIAN LITERATUR (11pt)}

\section{The Great Good Place oleh Ray Oldenburg}

Dahulu arsitektur memiliki fungsi yang jelas dan pasti, namun arsitektur diminta untuk terbuka dan peka terhadap perubahan fungsi dan program. Begitu juga dengan keberadaan third place, tempat ini dibtuhkan karena adanya rasa jenuh di antara first place dan second place. namun tentu saja membuat third place tidak semudah itu. Banyak permasalahan yang terjadi di dalamnya. Banyak sekali yang menjadi pertimbangan dalam membuat third place seperti, moderenisasi, kapital, gaya hidup, teknologi, jenis kelamin, umur, dan komunitas.

Berdasarkan buku "The Great Good Place" oleh Ray Oldenburg, berikut merupakan karakteristik Third Place, yaitu (1) On Neutral Ground: Sebuah kota memiliki ciri khas dan asosiasi yang beragam, dan itulah yang seharusnya menjadi potensi mereka. Tempat ini ada untuk semua individu dapat datang dan pergi secara netral, dimana mereka dapat merasa nyaman, (2) The Third Place Is A Leveler: Sebuah tempat yang bertujuan untuk menyatukan setiap individu, karena setiap individu secara tidak langsung terikat dalam beberapa tujuan. Tempat ini menjadi kesempatan untuk berkumpul dan bertemu dengan orang baru, tanpa memandang derajat seseorang, (3) Conversation Is The Main Activity: sebuah tempat yang memberikan rasa nyaman kepada individu terhadap semua aktivitas di dalamnya. Setiap aktivitas pasti membutuhkan sosiaslisasi karena itu sosialisasi menjadi peran yang sangat penting pada tempat ini, (4) Accessbility And Accomodation: sebuah tempat yang akan dikunjungi harus memberikan layanan yang terbaik dan terlengkap, sehingga setiap individu yang berada disini dapat merasa aman dan nyaman setiap saat, baik pada pagi hari, siang hari, maupun pada malam hari, (5) The Regulars: sebuah tempat yang akan dikunjungi harus memberikan citra yang baik sehingga setiap individu yang datang tanpa terberbani, dan menjanjikan mereka untuk datang kembali, dalam artian mereka menjadi pelanggan tetap untuk tempat ini, (6) A Low Profile: sebuah tempat harus memiliki citra yang sederhana, tanpa kemewahan. Sehingga tidak menjadi timpang sebelah kepada setiap individu yang datang. Tampilan yang megah akan membuat beberapa individu menjadi ragu akan tempat ini, dan (7) The Mood Is Playful: sebuah tempat harus memiliki nuansa yang hidup, agar setiap individu yang datang tidak merasa bosan. Setiap aktivitas yang ada harus terus hidup agar menciptakan suasana kecemasan ataupun keterasingan. 


\section{Happy City oleh Charles Montgomery}

Berdasarkan buku Happy City oleh Charles Montgomery, langkah pertama dalam merencanakan kota yang baik (Happy City), bukanlah sebuah perancangan, langkah ini tidak berkaitan sama sekali dengan bangunan, jalan, ataupun penghijauan. Kesejahteraan merupakan langkah pertama yang seharusnya kita pikirkan. Untuk mencapai sebuah lingkungan kota yang baik harus berada pada kondisi ini, (1) Kesejahteraan secara subyektif, (2) Kesejahteraan secara psikologis, dan (3) Kehidupan yang sehat.

Untuk mencapai kesejahteraan kota, terdapat 9 prinsip utama, yaitu (1) Core Needs: ini merupakan kebutuhan dasar yang tidak boleh tertinggal, seperti kebutuhan akan makanan, minuman, tempat tinggal, sanitasi, dan keamanan, (2) Social Relationships: hubungan sosial merupakan pendorong dari kesehatan dan kesejahteraan paling kuat. Kebahagiaan akan suatu materi lebih cepat pudar dibandingkan kebahagian dari ikatan sosial. Dengan bersosialikasi orang-orang yang bahagia akan menjadi lebih sehat secara fisik dan mental, mereka akan lebih produktif, (3) Health: kesehatan fisik merupakan salah satu prinsip penting dari kesejahteraan seseorang. Dengan kata lain, seseorang yang merasa sehat akan sama pentingnya dengen merasa bahagia, (4) Equity and Relative Status: perlu kita ketahui bahwa perbedaan status memiliki dampak ke psikologis. Individu yang berstatus lebih tinggi akan lebih sehat dan hidup lebih lama, daripada mereka yang berstatus rendah dengan pelayanan yang sama. Karena individu dengan status rendah cenderung lebih stres setiap harinya, (5) Ease: orang yang merasa nyaman akan mampu untuk menghadapi dan berkembang di tengah tantangan yang didapatinya setiap hari. Hal ini menjadikan mereka lebih bahagia dan rentan akan penyakit, (6) Joy: sebagian besar kebahagian orang bukan hanya ditentukan dari yang mereka alami saat ini, namun juga terhadap kenangan yang dilewatinya akan pengalaman baik atau buruk, (7) Meaning: kesejahteraan psikologis adalah sesuatu yang lebih dari sekedar kepuasan atau kesenangan. Karena seperti yang telah ditulis sebelumnya, itu hanya bersifat sementara. Kesejahteraan itu harus melibatkan perasaan bahwa hidup kita memiliki sebuah makna yang penting, dimana kita telah mengetahui tujuan dari kehidupan ini, mengetahui jati diri kita, (8) Belonging: selain dari makna hidup, masyarakat juga seharunya tahu tentang apa yang dia punya, namun bukanlah dalam hal materi. Mereka harus tau kemampuan apa yang mereka miliki, tempat yang baik membuat mereka tau apa kemampuan yang mereka miliki, dan (9) Resilience: orang mudah beradaptasi akan lebih tangguh dan memiliki sumber daya, pengetahuan, dan fleksibilitas yang lebih. Kota diharapkan dapat memberikan efek adaptasi yang lebih baik kepada masyarakat, seperti adanya perubahan iklim, cuaca panas, ataupun angin-angin kencang. Tujuannya agar membantu masyarakat dalam merespon, memulihkan, dan berkembang dalam menghadapi sebuah perubahan sosial, ekonomi, dan lingkungan.

\section{METODE}

Berikut merupakan metode pengumpulan data pada penelitian ini, (1) Metode Deskriptif: Metode berujuan untuk memberikan deskripsi secara faktual dan akurat terhadap kawasan Muara Baru, dan (2) Metode Komparatif: Melakukan perbandingan aktivitas para pengguna dan pengunjung kawasan Muara Baru untuk menilai kalangan-kalangan yang tereksklusi secara sosial.

\section{Metode Penngumpulan Data}

Berikut merupakan metode pengumpulan data pada penelitian ini, (1) Metode Studi Kepustakaan: Melakukan studi litelatur dengan hal-hal yang berkaitan dengan tema, (2) Metode Wawancara: Melakukan wawancara atau tanya jawab langsung kepada beberapa orang yang berada di kawasan Muara Baru, dan (3) Metode Observasi: Melakukan pengamatan pada kawasan Muara Baru, dan juga terhadap sumber-sumber pustaka yang ada. 


\section{Proses Pengelolahan Data}

Berikut merupakan metode pengelolahan data pada penelitian ini, (1) Dilakukan pengumpulan data sebanyak-banyaknya dari berbagai sumber yang ada mengenai data yang diperlukan, (2) menyeleksi data terakurat yang didapatkan, serta memilih yang berasal dari sumber terpercaya, (3) menyimpulkan data-data yang didapat dan digunakan sebagai acuan dalam penelitian, dan (4) melakukan penelitian dengan berbagai sumber yang telah ada dan menarik hasil dari kesimpulan tersebut

\section{DISKUSI DAN HASIL}

\section{Aktivitas Penduduk Kawasan Muara Baru}

First Place

Kondisi eksisting pada kawasan Muara Baru yang telah ditinjau berdasarkan hasil studi, wawancara, dan survei lapangan.

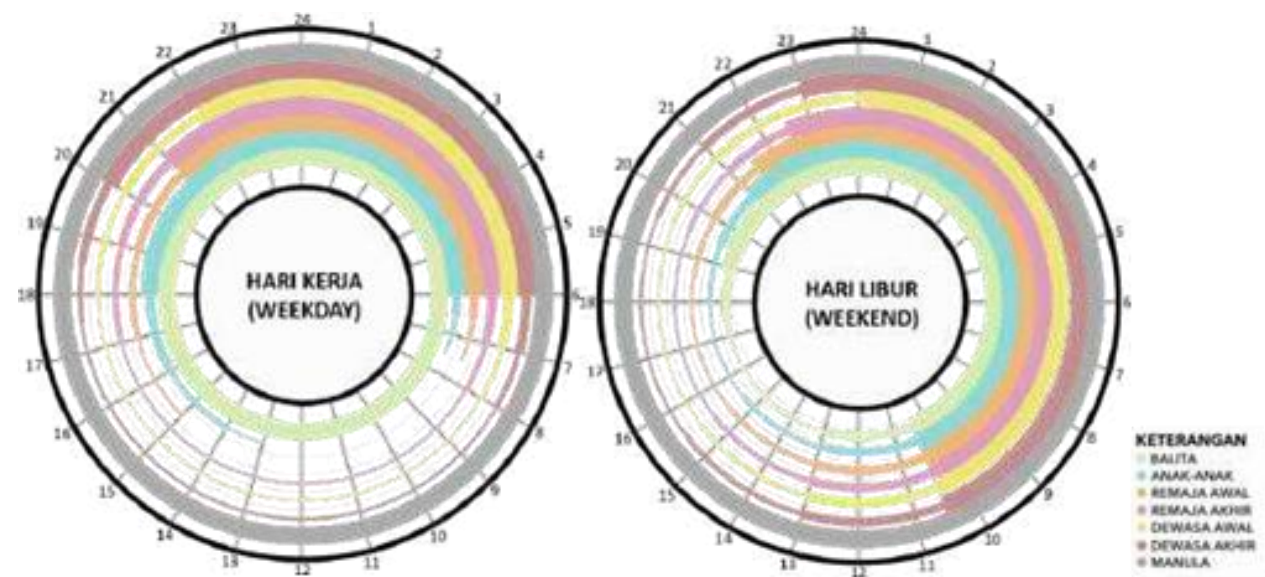

Gambar 1. Diagram Aktivitas Kawasan First Place Sumber: Penulis, 2020

Jika dilihat dari aktivitas pengguna, pada kawasan permukiman memiliki banyak kekurangan. Kondisi permukiman yang padat tanpa adanya ruang berkumpul akan sangat berpengaruh terhadap aktivitas penggunanya. Sehingga aktivitas pengguna menjadi terbatas, orang-orang lebih sering berada di dalam rumah.

\section{Second Place}

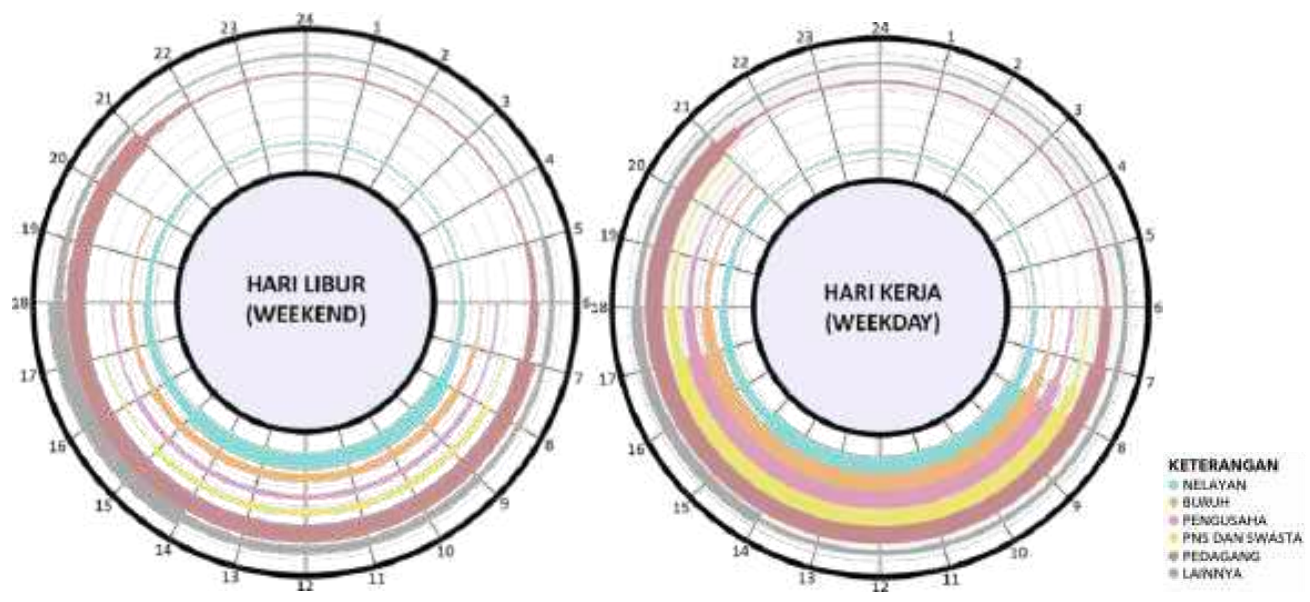

Gambar 2. Diagram Aktivitas Kawasan Second Place Sumber: Penulis, 2020 
Jika dilihat dari aktivitas pengguna, pada kawasan permukiman sudah cukup baik. Yang menjadi kendala pada kawasan second place ini hanyalah tidak banyak bangunan komersial sebagai hiburan para pengguna. Sehingga aktivitas pengguna menjadi sangat monoton, orangorang tidak banyak berinteraksi di dalam kawasan.

\section{Identifikasi Masalah}

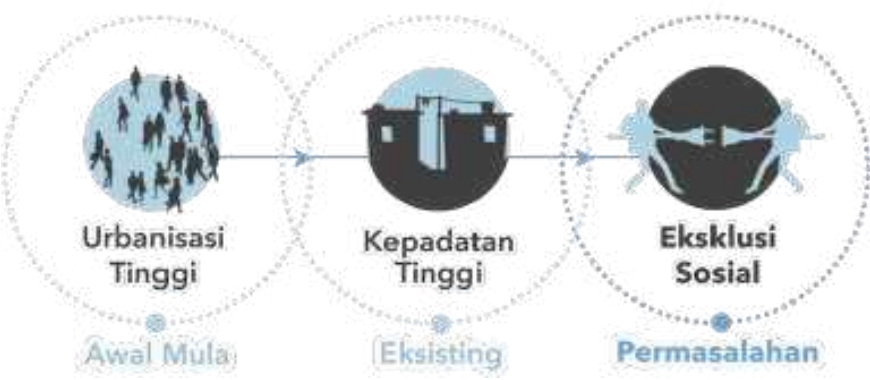

Gambar 3. Diagram Isu Utama Kawasan Muara Baru

Sumber: Penulis, 2020

\section{Awal Mula (Urbanisasi Tinggi)}

Dahulu kawasan Muara Baru belum padat, kawasan ini masih dipenuhi rawa-rawa dan perkebunan lainnya. Semenjak Pelabuhan Samudera (PPS) Nizam Zachman sudah mulai beroperasi pada tahun 1986, urbanisasi pada kawasan Muara Baru meningkat.

\section{Eksisting (Kepadatan Tinggi)}

Akibat dari tingkat urbanisasi yang tinggi, kepadatan secara horizontal pun meningkat, dengan angka kepadatan berkhisar 80 rumah/km. Berdasarkan buku The Challenge of Slums: Global Report on Human Settlements oleh UN-Habitat (2003), kawasan permukiman Muara Baru dapat dikategorikan sebagai kawasan kumuh, dengan identitas kawasan kumuh, yaitu (1) kurangnya layanan dasar, (2) perumahan di bawah standar atau struktur bangunan yang ilegal, (3) kepadatan tinggi dan penuh sesak, (4) kondisi hidup yang tidak sehat dan lokasi yang berbahaya, dan (5) ukuran tanah. Kondisi eksistingnya akan mempengaruhi personel seseorang, salah satunya adalah timbulnya eksklusi sosial antar individu.

Permasalahan (Eksklusi Sosial).

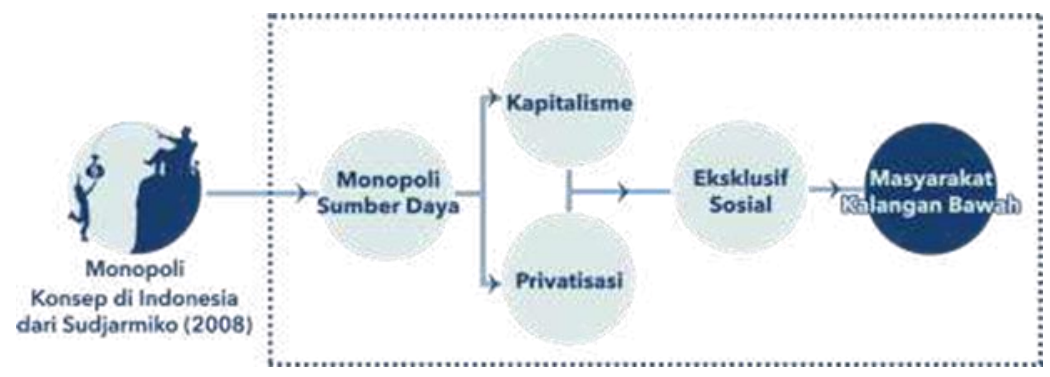

Gambar 4. Konsep Eksklusif Sosial di Indonesia

Sumber: Sudjatmiko, 2008

Konsep eksklusi sosial masih jarang digunakan di Indoensia, Sudjatmiko (2008) telah menggunakan konsep ini. la cenderung menggunakan paradigma monopoli sebagai dasar analisisnya. Salah satu contoh dalam tulisannya, "...dalam institusi lain seperti sekolah dan tempat bekerja, pendidikan gratis dan pasar kerja tidak menetapkan kuota untuk kalangan masyarakat bawah. Ini mirip dengan pasar bebas tapi tidak adil dimana pelaku usaha kecil seharusnya mendapat perlindungan, dan monopoli oleh pengusaha besar seharusnya 
dicegah". Dalam tulisannya yang lain, yang dimuat pada edisi khusus, Sudjatmiko mengamati masyarakat kalangan bawah tereksklusi akibat dari sistem privatisasi dan kapitalisme. Pada sebuah artikel milik Kartika (2018) menuliskan, "Salah satu warga RT 20 RW 17 Kelurahan Penjaringan, Suminah (54) mengatakan warga di Muara Baru masih kesulitan air bersih". Secara tidak langsung, konsep eksklusi sosial tersebut mungkin sudah terjadi di kawasan Muara Baru.

\section{Perumusan Ide}

Isu-isu eksklusi sosial tercipta dari urbanisasi yang tinggi dan kepadatan yang tinggi. Kedua hal tersebut mungkin terlihat negatif, namun kedua hal tersebut dapat menjadi strategi dalam menyusun program pada kawasan, (1) strategi dan tantangan dari urbanisasi tinggi: salau satu penyebab eksklusi sosial adalah urbanisasi yang tinggi, sehingga kawasan tersebut ditempati oleh masyarakat dari luar Jakarta. Hal itu menjadi potensi, yaitu ragam budaya; masyarakat yang dari berbagai daerah. Namun juga menciptakan tantangan baru, yaitu munculnya kelompok radikal, (2) Strategi dan tantangan dari kepadatan tinggi: salah satu penyebab eksklusif sosial adalah kepadatan yang tinggi, sehingga banyak penduduk di kawasan tersebut. Hal ini menjadi potensi, yaitu adanya sumber daya manusia (SDM). Namun juga menciptakan tantangan baru, SDM yang belum berkembang.

\section{Program Ruang}

Program Ruang pada perancangan ini terdapat 2 program utama yaitu, program edukasi dan sosial. Untuk memenuhi kebutuhan program utama maka terdapat 2 program pendukung, yaitu program penunjang dan servis.

\section{Program Edukasi}

Program edukasi dibentuk dengan tujuan untuk meningkatkan kemampuan dan kualitas dari individu mulai dari perfoma, kinerja, karakteristik, dan identitas dari individu dalam aspek pengembangan di bidang seni budaya, sehingga nantinya akan menghasilkan SDM yang lebih baik, dan diharapkan dapat membantu individu tersebut menjadi personel yang lebih baik dalam lingkupnya.

Tabel 1. Program Ruang Edukasi

\begin{tabular}{|c|c|c|c|c|}
\hline $\begin{array}{c}\text { Ruang } \\
\text { (Jumlah) }\end{array}$ & Keterangan & Pengguna & Zona & $\begin{array}{l}\text { Luas } \\
\text { (Kap.) }\end{array}$ \\
\hline $\begin{array}{l}\text { Edukasi Litelatur } \\
\text { (Min. } 2 \text { Ruang) }\end{array}$ & $\begin{array}{l}\text { Ditargetkan untuk anak dan } \\
\text { remaja untuk mempelajari } \\
\text { tentang kebudayaan secara } \\
\text { litelatur. }\end{array}$ & $\begin{array}{l}\text { Pengunjung } \\
\text { Tertentu }\end{array}$ & Privat & $\begin{array}{c}120 \mathrm{~m}^{2} \\
\text { (120 Orang) }\end{array}$ \\
\hline $\begin{array}{l}\text { Open Class } \\
\text { (Min.1 Ruang) }\end{array}$ & $\begin{array}{l}\text { Ditargetkan untuk para IRT, } \\
\text { Pekerja, dan Manula agar lebih } \\
\text { nyaman untuk belajar Bersama. }\end{array}$ & $\begin{array}{l}\text { Pengunjung } \\
\text { Tertentu }\end{array}$ & Semi Publik & $\begin{array}{c}400 \mathrm{~m}^{2} \\
\text { (100 Orang) }\end{array}$ \\
\hline $\begin{array}{l}\text { Perpustakaan } \\
\text { (1 Ruang) }\end{array}$ & $\begin{array}{l}\text { Tempat kumpulan sumber- } \\
\text { sumber kebudayaan, tidak dapat } \\
\text { dibawa pulang (hanya dipinjam di } \\
\text { tempat). }\end{array}$ & $\begin{array}{l}\text { Semua } \\
\text { Orang }\end{array}$ & Semi-Privat & $\begin{array}{c}100 \mathrm{~m}^{2} \\
\text { (70 Orang) }\end{array}$ \\
\hline $\begin{array}{l}\text { Mini Theater } \\
\text { (1 Ruang) }\end{array}$ & $\begin{array}{l}\text { Ruang belajar dengan memutar } \\
\text { video-video kebudayaan yang } \\
\text { tersedia. }\end{array}$ & $\begin{array}{l}\text { Pengunjung } \\
\text { Tertentu }\end{array}$ & Privat & $\begin{array}{c}100 \mathrm{~m}^{2} \\
\text { (60 Orang) }\end{array}$ \\
\hline $\begin{array}{l}\text { Studio Musik } \\
\text { (Min. } 2 \text { Ruang) }\end{array}$ & $\begin{array}{l}\text { Ruang belajar musik tradisional } \\
\text { dan targetnya adalah semua } \\
\text { orang. }\end{array}$ & $\begin{array}{l}\text { Pengunjung } \\
\text { Tertentu }\end{array}$ & Privat & $\begin{array}{c}120 \mathrm{~m}^{2} \\
\text { (50 Orang) }\end{array}$ \\
\hline $\begin{array}{l}\text { Studio Tari } \\
\text { (Min. } 2 \text { Ruang) }\end{array}$ & $\begin{array}{l}\text { Ruang belajar tarian tradisional } \\
\text { dan targetnya adalah semua } \\
\text { orang. }\end{array}$ & $\begin{array}{l}\text { Semua } \\
\text { Orang }\end{array}$ & Semi-Privat & $\begin{array}{c}120 \mathrm{~m}^{2} \\
\text { (50 Orang) }\end{array}$ \\
\hline \multirow[t]{2}{*}{$\begin{array}{l}\text { Ruang Diskusi } \\
\text { (Min. } 2 \text { Ruang) }\end{array}$} & $\begin{array}{l}\text { Ruang berkumpul untuk kelas } \\
\text { dan kegiatan lainnya. }\end{array}$ & $\begin{array}{l}\text { Pengunjung } \\
\text { Tertentu }\end{array}$ & Privat & $\begin{array}{c}100 \mathrm{~m}^{2} \\
\text { (40 Orang) }\end{array}$ \\
\hline & & & $\begin{array}{r}\text { Total } \\
\text { Sirkulasi } 40 \% \text { ) }\end{array}$ & $1.484 \mathrm{~m}^{2}$ \\
\hline
\end{tabular}




\section{Program Sosial}

Program sosial dibentuk dengan tujuan untuk mengumpulkan orang-orang tanpa memandang ras, agama, gender, dan lain sebagainya. Ruang tercipta diharapkan netral dan nyaman agar antar individu dapat terbuka dan bebeas berekspresi, sehingga pada akhirnya akan mengurangi dari ruang eksklusif sosial mereka.

Tabel 2. Program Ruang Sosial

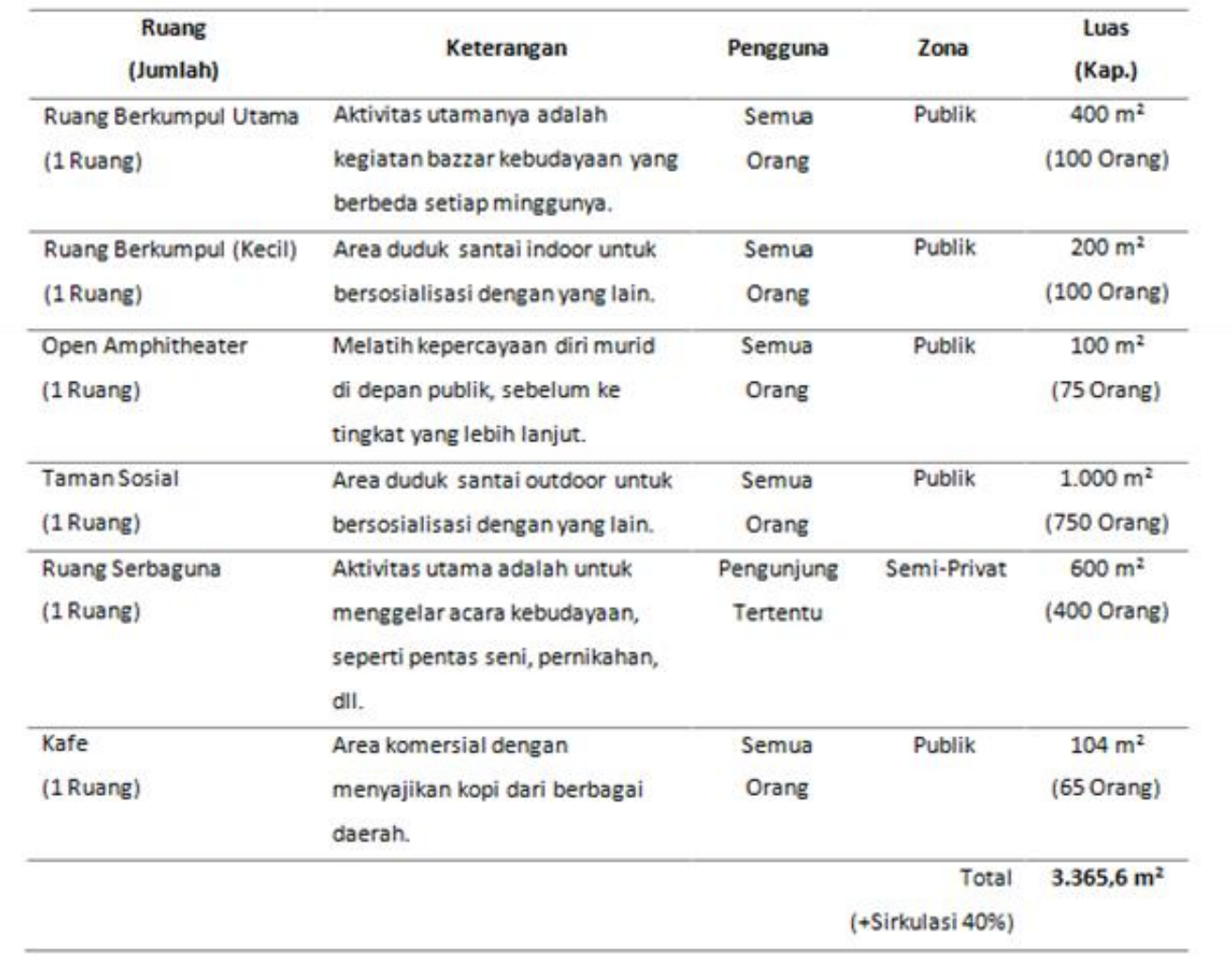

Sumber: Penulis, 2020

\section{Program Pendukung}

Program pendukung dan servis dibentuk sesuai dengan kebutuhan dari program utama yaitu, program edukasi dan program sosial. Selain itu program ini ada menjadi kelengkapan untuk sekitarnya terhadap bangunan.

\section{Analisis Tapak}

Tabel 3. Analisis Tapak

\begin{tabular}{|l|l|l|}
\hline Gambar & \multicolumn{1}{|c|}{ Potensi } & \multicolumn{1}{|c|}{ Analisis } \\
\hline Sinar matahari & $\begin{array}{l}\text { Bagian Kiri dan Kanan } \\
\text { merupakan bagian yang } \\
\text { paling banyak disinari } \\
\text { matahari. }\end{array}$ & $\begin{array}{l}\text { Sehingga pada arah kiri dan } \\
\text { kanan bangunan akan dibuka } \\
\text { bangunan yang banyak untuk } \\
\text { menghemat daya } \\
\text { pencahayaannya. }\end{array}$ \\
\hline
\end{tabular}




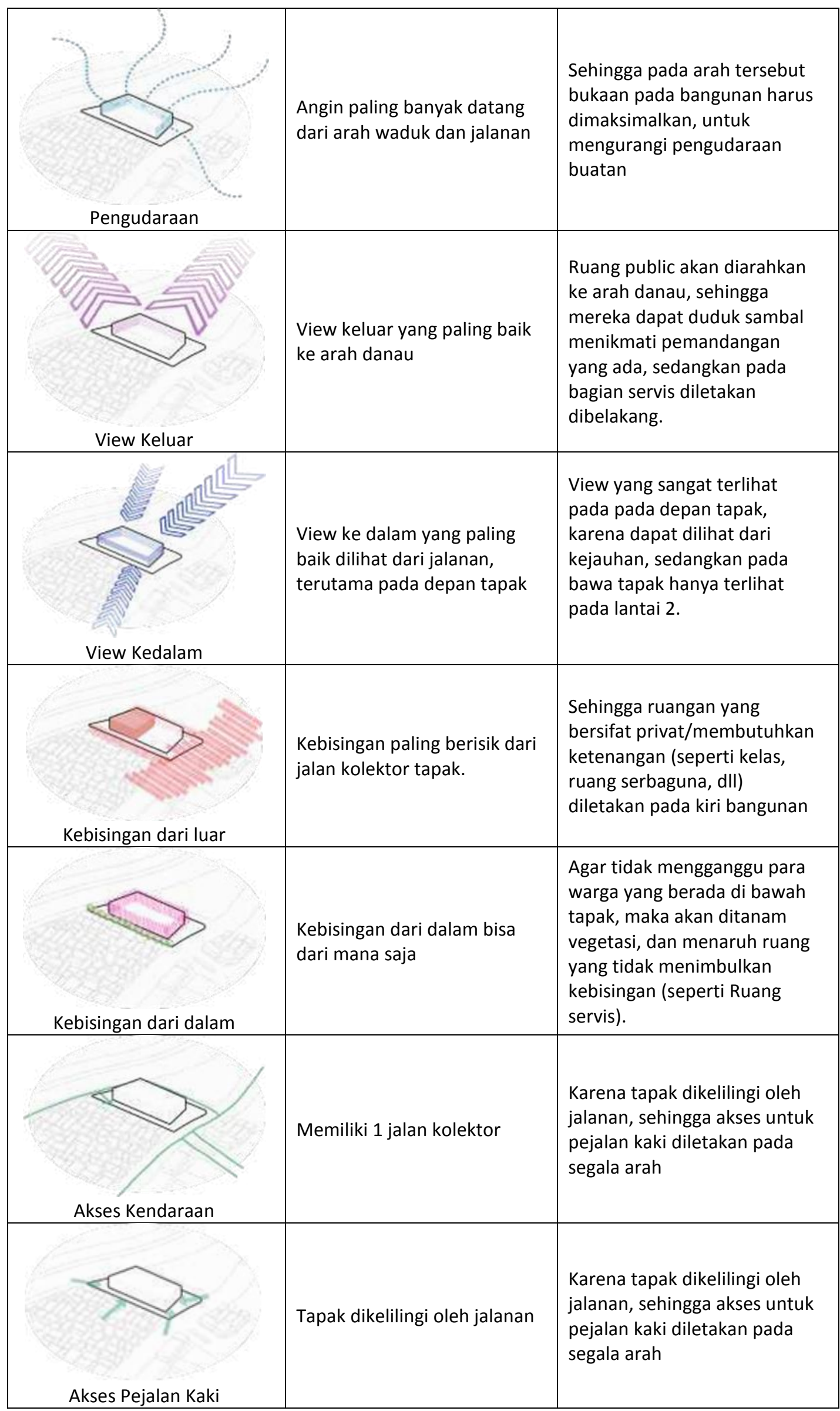

Sumber: Penulis, 2020 


\section{Transformasi Bentuk}

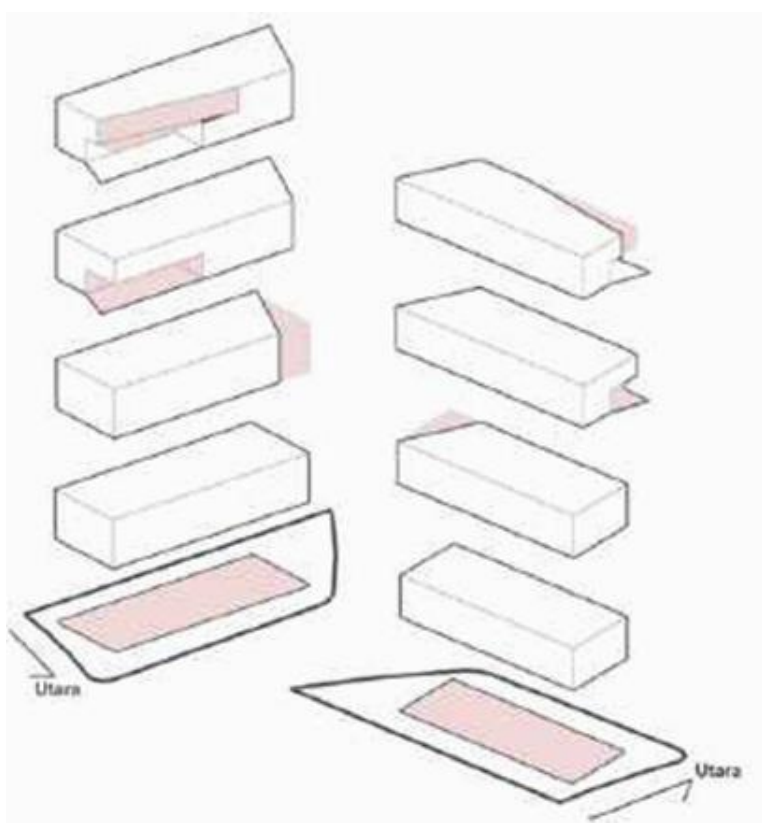

Gambar 5. Proses Gubahan Massa

Sumber: Penulis, 2020

\section{Konsep Bangunan}

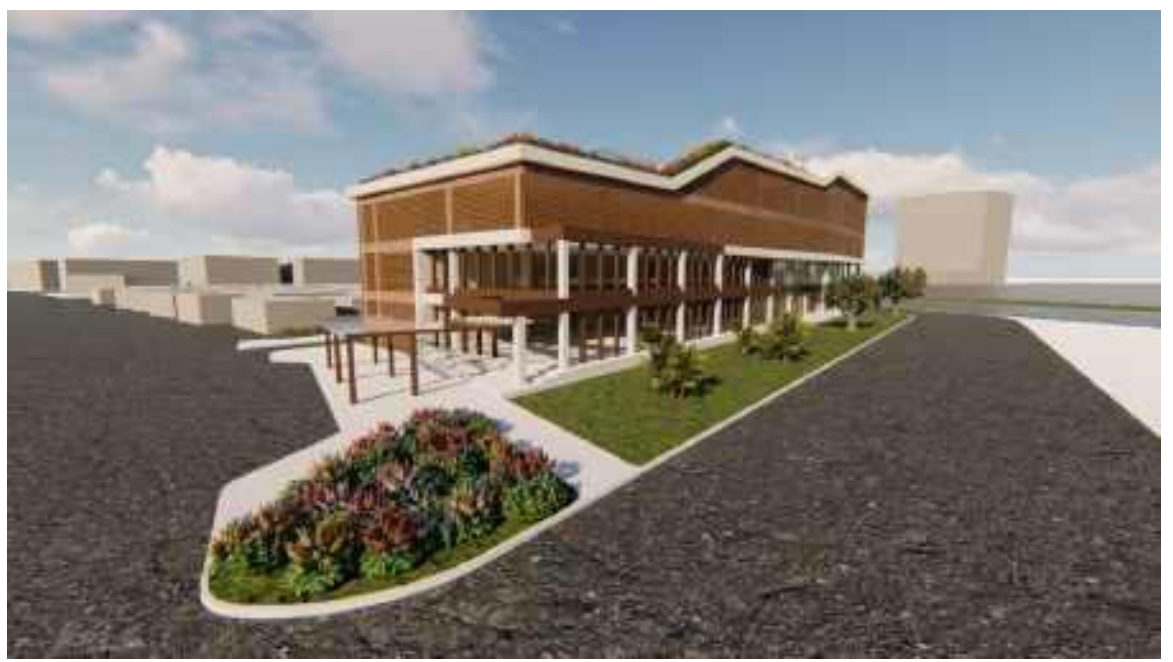

Gambar 6. Perspektif Eksterior

Sumber: Penulis, 2020

Fasad bangunan dirancang dengan sesederhana mungkin tanpa adanya rasa kemewahaan, untuk menyesuaikan dengan keadaan sekitarnya. Fasad bangunan bersifat terbuka dengan tujuan dapat menyambut tamu agar mereka merasa nyaman di dalamnya. Selain itu konsep terbuka bertujuan agar pencahayaan dan pengudaraan alami dapat masuk dengan maksimal, karena letaknya cukup strategis di pinggir danau, sehingga akan terasa lebih sejuk, sehingga bukaan pada bangunan harus banyak, agar dapat mengurangi penggunaan listrik 


\section{Hasil Perancangan}

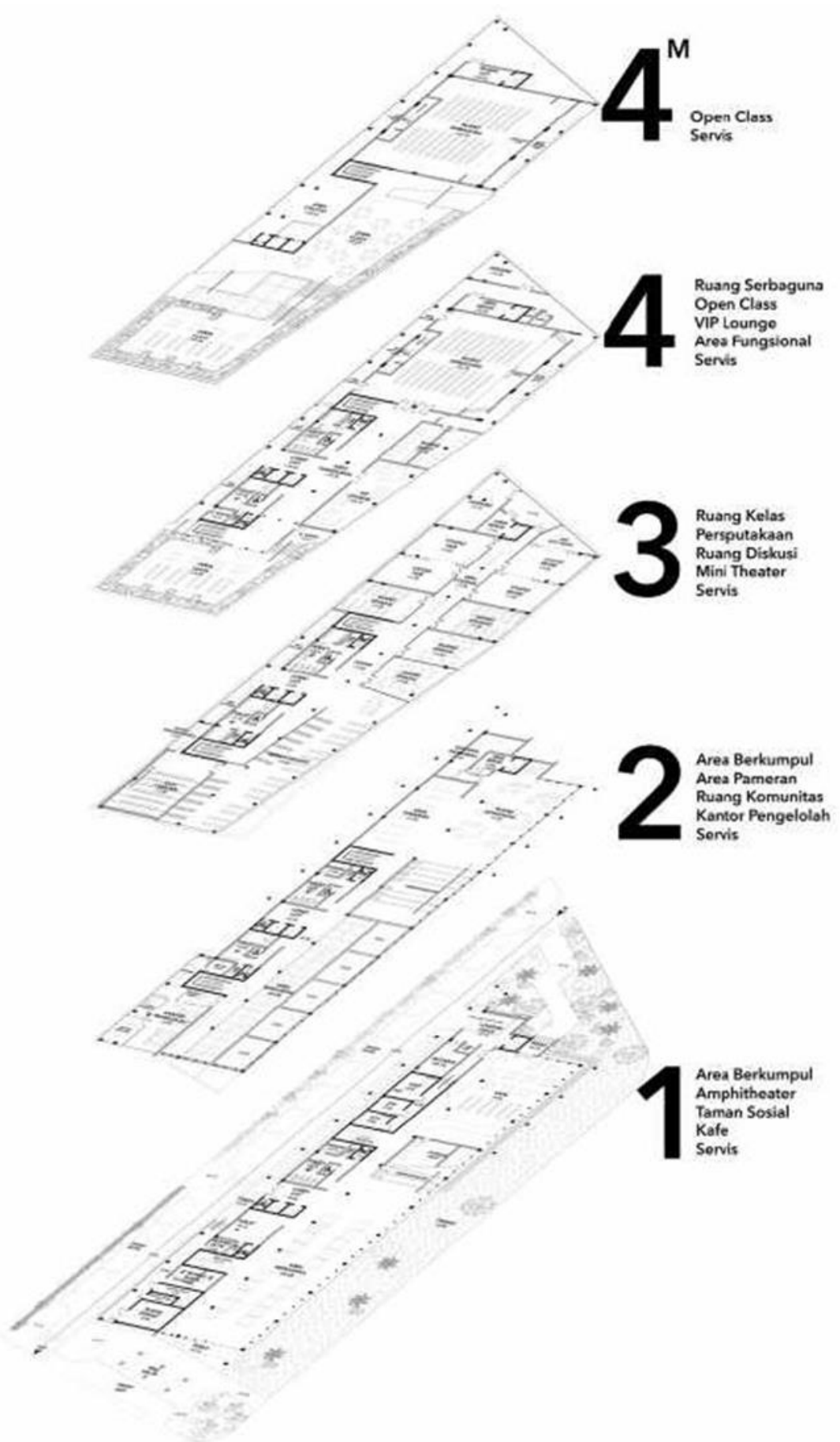

Gambar 7. Denah Aksonometri Perancangan

Sumber: Penulis, 2020

Pembagian ruang setiap lantai berdasarkan zonasi dan aktivitasnya. Zona dan aktivitas yang membutuhkan ketenangan (privat) seperti ruang-ruang kelas, ruang diskusi dan sebagainya, akan diletakan di lantai atas untuk menghindari kebisingan dari luar dengan akses pengunjung yang terbatas. Sedangkan untuk lantai-lantai bawah merupakan zona publik, seperti ruang berkumpul, kafe, dan sebagainya, sehingga orang-orang dapat berkumpul dan bersosialisasi. Selain itu di lantai bawah juga terdapat zona servis untuk kebutuhan MEP, dan letaknya 1 meter di bawah lantai 1 , sehingga zona tiap fungsi tidak tercampur. 

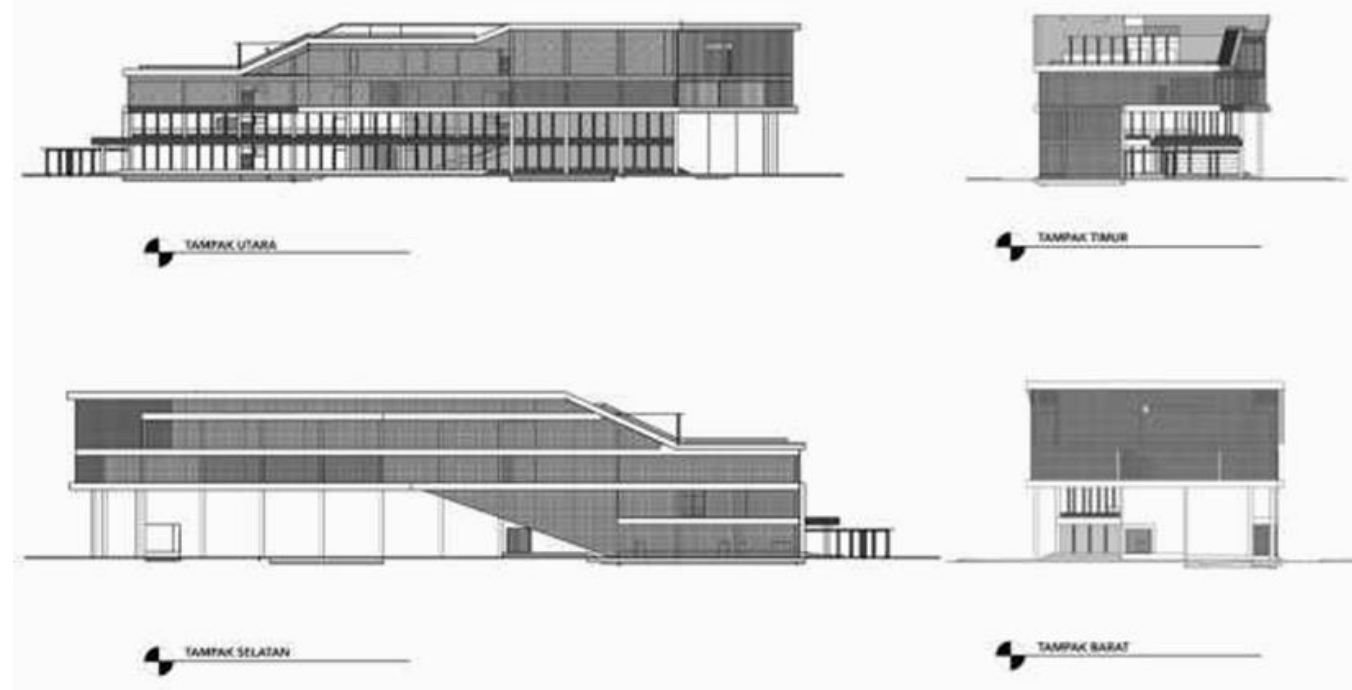

Gambar 8. Tampak Perancangan

Sumber: Penulis, 2020

Fasad bangunan dirancang sederhana mungkin, dengan material utamanya bambu, kayu, dan beton. Pada setiap sisi bangunan memiliki pintu masuk, namun pintu masuk utama berada pada tampak timur. Tampak utara sebagian besarnya bersifat terbuka karena langsung terhubung dengan taman, sehingga orang dapat dengan nyaman berkumpul pada area tersebut.

\section{KESIMPULAN DAN SARAN}

\section{Kesimpulan}

Hasil rancangan ini ditujukan untuk masyarakat kawasan Muara Baru dapat meningkatkan kualitas performa individu dan menjadi individu semakin terbuka dan mau membuka diri terhadap sekitarnya. Dengan adanya program-program dengan basis sosiokultural, mengupayakan agar mereka dapat menghilangkan rasa eksklusif sosial antar individu, dan terbentuknya individu yang lebih baik. Sehingga pada akhirnya masyarakat yang akan mengembangkan kawasan menjadi lebih produktif.

\section{Saran}

Berdasarkan hasil penelitian dan kesimpulan yang telah dijelaskan sebelumnya, penulis memberikan beberapa saran, yaitu (1) Infrastruktur di kawasan Muara baru, seperti jalan, dapat terbangun sesuai perancangang, sehingga menjadikan tempat ini lebih mudah diakses dan menjadi lebih baik, (2) Adanya penertiban pada pedestrian bagi para pelanggar yang memakai pedestrian sebagai kebutuhan pribadi, hal ini bertujuan agar pedestrian dapat difungsikan dengan maksimal, dan (3) Adanya revitalisasi terhadap waduk secara rutin, agar dapat mengurangi banjir yang ada pada kawasan ini.

\section{REFERENSI}

Berina, D. (2011). Strategi Biaya Adaptasi Masyarakat Teluk Jakarta Terhadap Dampak Banjir ROB Akibat Perubahan Iklim. Skripsi Institut Pertanian Bogor, 30-39.

BPS Kota Administrasi Jakarta Utara. (2019). Kecamatan Penjaringan Dalam Angka 2019. Jakarta: CV. Nario Sari

BPS Kota Administrasi Jakarta Utara. (2019). Staistik Kesejahteraan Rakyat Kota Jakarta Utara 2019. Jakarta: CV. Nario Sari.

Hanim, F. (2007). Analisis Kebijakan Pemanfaatan Pelabuhan dalam Kerangka Pengelolaan Lingkungan di Pelabuhan Perikanan Samudera (PPS) Nizam Zachman Jakarta, Provinsi DKI Jakarta. Skripsi Institut Pertanian Bogor, 37-112. 
Montgomery, C. (2013). Happy City: Transforming Our Lives Through Urban Desain. Amerika: Farrar, Straus and Giroux, Random House, dan Penguin Books. Oldenburg, Ray. (1999). The Great Good Place: Cafes, Coffee Shops, Bookstores, Bars, Hair Salons, and Other Hangouts at the Heart of a Community. Amerika: Da Capo Press.

Nurdin, M. F. (2015). Ekslusif Sosial dan Pembangunan: Makna, Fokus dan Dimensi untuk Kajian Sosiologis. Makalah Kegiatan Kongres II Asosiasi Program Studi Sosiologi Indonesia dan Konferensi Nasional Sosiologi Indonesia IV, 11-15

Silver, H. (1994). Social Exclusion and Social Solidarity: Three Paradigms. International Labour Review, 133, 531-578.

Sudjatmiko, I. G. (2008). Social Inclusion and Social Transformation in Indonesia. Makalah The Annual Conference of Human Development and Capability Association New Delhi, 10-13.

Syahra, R. (2010). Eksklusif Sosial: Perspektif Baru untuk Memahami Deprivasi dan Kemiskinan. Jurnal Masyarakat \& Budaya, Edisi Khusus, 10-30.

United Nation Human Settlement Programme (UN-Habitat). (2003). The Challenge of Slums: Global Report on Human Settlements 2003. London: Earthscan Publication Lt.d.

Aprialim, B. (2017). Sosiokultural dalam Komunikasi Kesehatan. Diakses pada 20 April 2020, dari https://www.kompasiana.com/bellalim/59fe04e0f33a2d4e1870bab2/ sosiokulturaldalam-komunikasi-kesehatan.

Kartika, M. (2018). Warga Muara Baru Beli Air Bersih Setiap Harinya. Diakses pada 18 Maret 2020, dari https://republika.co.id/berita/nasional/jabodetabek-Nasional

/18/12/12/pjl5au368-warga-muara-baru-beli-air-bersih-setiap-hari.

Mardiansyah, W. (2017). Menelusuri RW 17 Penjaringan, Kawasan Terkumuh di Jakarta. Diakses pada 21 Maret 2020, dari https://www.medcom.id/nasional/0kpnV1qNmenelusuri-rw-17-penjaringan-kawasan-terkumuh-di-jakarta.

Pratama, N. I.. (2018). Kampung Muara Baru dan Identitas. Diakses pada 16 Maret 2020, dari https://rujak.org/kampung-muara-baru-dan-identitas/.

Setiawan, M. (2018). Modal Sosial Kultural dalam Pembangunan Ekonomi Nasional. Diakses pada 20 April 2020, dari https://www.kompasiana.com/mahbubs/5a62ce19f1 3344071d2a7e32/modal-sosial-kultural-dalam-pembangunan-ekonomi-nasional.

Wilibrordus, M (2013). 50 Tahun Lalu, Waduk Pluit Jernih. Diakses pada 16 Maret 2020, dari https://megapolitan.kompas.com/read/2013/05/22/08551456/50.tahun.

lalu.waduk.pluit.jernih.haha 